\title{
Towards a circular economy: insights based on the development of the global ENGAGE-materials model and evidence for the iron and steel industry
}

\author{
Matthew Winning ${ }^{1}$ - Alvaro Calzadilla ${ }^{1}$. \\ Raimund Bleischwitz ${ }^{1}$ - Victor Nechifor ${ }^{1}$
}

\begin{abstract}
A number of recent economic modelling studies have attempted to analyse resource efficiency and the circular economy. However, modelling analysis in this area is relatively underdeveloped. In particular, many CGE models are unable to provide significant insight given their aggregated sectoral coverage. Here we describe the development of the Environmental Global Applied General Equilibrium (ENGAGEmaterials) model created to consider the economic and sectoral effects of potential policies on a circular economy and resource efficiency, which affect materials and resources at the stages of extraction, production and recycling. Our policy scope is global with a special emphasis on China and Europe, as both regions have dedicated policies in place and indicate their willingness to take the lead. The case of steel is relevant as it is a key material for all economies across the world and offers a range of interesting features for circularity and sustainability. ENGAGE-materials models iron ore mining, primary production of iron and steel, secondary production of iron and steel, and steel scrap recycling at the global level. We utilise this technology rich framework to provide preliminary results on scenarios comprising economic insights into a saturation effect and straightforward policy such as doubling the availability of secondary steel.
\end{abstract}

Keywords Resource efficiency · Circular economy · Recycling · Iron and steel · Computable general equilibrium

JEL classification E1 $\cdot \mathrm{Q} 3 \cdot \mathrm{Q} 5$

Alvaro Calzadilla

a.calzadilla@ucl.ac.uk

1 Institute for Sustainable Resources, University College London, Central House, 14 Upper Woburn Place, London WC1H 0NN, UK 


\section{Introduction}

There has been significant interest from policymakers recently towards creating a circular economy and resource efficient future (European Commission 2015) and there appears to be potential to improve the efficiency of how resources are utilised and it is suggested that potential economic and environmental benefits may arise (UNEP 2017). Also, reusing and recycling of materials is fundamental to achieve a global resource efficiency in consumption and production as aimed by the Sustainable Development Goals. Understanding the role that specific resource flows and prices can have on the wider economy and trade patterns is essential when deciding how to implement policies to achieve such goals.

The resource nexus concept considers broad categories of energy, land, water, biomass and food, and materials. Resource efficiency can pertain to the improved use (achieving the same output with less inputs) of any of these resources in the production of goods and services in a sustainable manner. The circular economy concept often goes hand in hand with resource efficiency, and refers to an economy in which waste and pollution are reduced to zero or negligible levels through increased recycling and better management. It requires movement away from the make, use, dispose incumbent cycle of production towards a method of production which achieves maximum value from resources for as long as possible. Therefore a circular economy should improve resource productivity as well as reduce waste and pollution and tackle scarcity price volatility issues. Altogether this is expected to have positive impacts on competitiveness and economic performance, yet all such impacts need to be assessed preferably at an international scale.

Resources use interlinkages and interdependencies are complex issues which require understanding across countries, sectors and resources with scarcity, volatility and politics being important issues (Chatham House 2012). Material and mineral use in economic activity is an area which is often studied within a partial equilibrium framework or from the perspective of a specific economic sector or industry e.g. iron and steel. However, there is often knock-on and indirect effects of changes in materials through prices and policies as well as technology change, and the full extent of these effects can only be captured through multi-sectoral modelling representing the whole economic system. Therefore the development of economy-wide or integrated modelling frameworks with a focus on materials is important. Recently materials and minerals have been seen through the concepts of resource efficiency and the circular economy (CE and BioIS 2015; Meyer et al. 2015; Ellen MacArthur Foundation and McKinsey Center for Business and Environment 2015).

In this paper we outline the motivation for, and give details of, the development of a global computable general equilibrium (CGE) model which will enable global analysis of changes in materials throughout the supply chain and allow us to properly consider the resource efficiency and circular economy impacts of different policy, political and technology futures. In particular we describe the development of modelling capability which can focus in greater detail on the areas of resource extraction, industrial processes and material recycling, all of which are essential aspects of understanding how to improve the circular economy. The global CGE model - ENGAGE-materials will allow us to consider the economic and sectoral effects of policies and shocks which affect materials and resources, and a global analysis is a requirement in order to identify 
any leakage of resource use as well as understanding trade patterns and economic interdependencies. In the first instance we focus on the inclusion of steel into the model. We consider steel - including its supply chain along iron ore, steel applications and re-use of scrap steel - as relevant because (i) steel production, consumption and trade matter for a macro-economic perspective and (ii) steel is seen as environmentally intensive, yet is also allows for almost infinite recycling and thus offers a perspective to innovate. To our best knowledge, this is the first attempt to include steel in such perspective into a global CGE model. However, future work will extend the process to include other metals and potentially non-metallic minerals in a similar manner.

This paper details the novel contribution of our model development and efforts which will allow for a greater understanding of the role that global material flows from specific industries, such as steel, can have on major economies and international trade as well as their role in achieving resource efficiency and circular goals. Section 2 provides a literature and model review of macro-economic analyses focussed on resource efficiency and the circular economy as well as more specific iron and steel modelling. Section 3 details all the elements of the ENGAGE-materials model development including data sources, regional and sectoral coverage, steel sector disaggregation and main characteristics of the model production structure. Section 4 then provides results from an example circular economy policy scenario. Section 5 concludes with an overall summary and perspectives on future applications and research questions related to international economics, economic policy and sustainable resources.

\section{Literature and model review}

In general macro-economic models do not capture the flow of physical materials through economies, and thus a prerequisite of modelling resource efficiency and the circular economy is omitted. As a result, analysis of global commodity markets is fairly difficult. Even those that do often lack the sectoral detail to consider the life-cycle of specific materials. One may compare this area in relation to materials with that of energy and climate change modelling, where more sophisticated economic tools have been developed over the last years to allow for the consideration on energy and environmental policies. In Section 2.1 we discuss various modelling approaches that have been developed with regards to both resource efficiency and circular economy studies, and then in Section 2.2 we focus more specifically on the iron and steel sector.

\subsection{Resource efficiency and circular economy modelling}

Bohringer and Rutherford (2015) developed a multi-regional CGE model for the Ellen MacArthur foundation (Ellen MacArthur Foundation and McKinsey Center for Business and Environment 2015) with a specific focus on the circular economy. They state the importance of a global model to ensure that important spill-over and feedback effects are fully captured. Bohringer and Rutherford (2015) define three key principles relating to the circular economy concept as being: (i) preservation of natural capital, (ii) maintenance of the highest utility of products, components and materials, and (iii) the avoidance of leakage. They state that resource allocation can be altered either by policy 
interference, such as resource taxes or technology mandates, or can be driven by technological change. The analysis specifically concentrates on efficiency improvements and technology shift in private transport, housing, and food sectors.

In the Bohringer and Rutherford's model the world is split into 5 regions (EU, North America, Other OECD, China and ROW) which each have 16 economic sectors. ${ }^{1}$ The model focuses in detail on transport, energy, households and food, and therefore it omits some relevant areas. More specifically, there is almost no representation of other minerals and materials except with the construction sector and motor vehicles. Private transportation is split out from other household consumption into a separate final demand. The analysis shows the benefits that circular economy can have on the economy and jobs, the results show that GDP could be $11 \%$ higher in 2030 and $20 \%$ higher in 2050 than the baseline development scenario. However, the authors are keen to stress that the technology improvement assumptions are exogenous and as such the model does not account for the costs required to achieve the technological change. While $\mathrm{CO}_{2}$ emissions are linked to fossil fuel use using fuel specific coefficients, there does not appear to be any physical materials modelled beyond gas, coal and oil. In particular, steel is aggregated together with the majority of other types of manufacturing, also there is no a material flow analysis on materials which are used, and thus there is a limit on their ability to consider circular economy policies.

The EXIOMOD model was developed by TNO in the Netherlands using the EXIOBASE dataset (developed under the EXIOPOL and CREEA projects) to create a global environmentally-orientated computable general equilibrium model which could consider resource efficiency questions for Europe and beyond. EXIOBASE2 is currently calibrated to 2007 although a new dataset is to be released soon with 2011 as a base year. While similar to standard global CGE models through representative agent's utility maximisation or cost minimisation, there is the additional inclusion of adaptive expectations and semi-endogenous technological change. EXIOMOD is large with 43 regions and 129 economic sectors, although the model is often run with higher aggregations, and 5 households differentiated by income quantiles. The incorporation of environmental quality into the households utility function is a novel and beneficial addition. In terms of resource efficiency and the circular economy, the EXIOMOD's detail is significant with 28 types of emissions, waste, land use, and material resources. There are eleven extraction sectors in the model, given in Table 1, which cover a number of important resources which can then be traced throughout the production process to end use and final demand.

The incorporation of both physical and monetary data in the model is essential for the environmentally extended analysis. Data on both domestic extraction used and unused in Kt/M EUR are included for primary crops, crop residues, fodder crops, timber, grazing, animals, metal ores, non-metallic minerals, and fossil fuels. The model also contains two specific material recycling sectors - recycling of metal waste and scrap, and recycling of non-metal waste and scrap. Waste is also considered more indepth with separate sectors for: collection and treatment of sewage, collection of waste,

\footnotetext{
${ }^{1}$ These sectors are coal, crude oil, natural gas, refined oil, electricity, air transport, water transport, other transport, manufacturing and services, motor vehicles, trade, construction, dwellings and other business services, beverages and tobacco, food, and all other goods.
} 
Table 1 EXIOBASE mining sectors

\begin{tabular}{ll} 
NACE Rev. 1.1 Code & EXIOBASE sector \\
\hline i11.a & $\begin{array}{l}\text { Extraction of crude petroleum and services related to crude oil extraction, excluding } \\
\text { surveying } \\
\text { Extraction of natural gas and services related to natural gas extraction, excluding } \\
\text { surveying } \\
\text { Extr.b }\end{array}$ \\
i11.c & Mining of uranium and thorium ores \\
i12 & Mining of iron ores \\
i13.1 & Mining of copper ores and concentrates \\
i13.20.11 & Mining of nickel ores and concentrates \\
i13.20.12 & Mining of aluminium ores and concentrates \\
i13.20.13 & Mining of precious metal ores and concentrates \\
i13.20.14 & Mining of lead, zinc and tin ores and concentrates \\
i13.20.15 & Mining of other non-ferrous metal ores and concentrates \\
i13.20.16 & Quarrying of stone \\
i14.1 & Quarrying of sand and clay \\
i14.2 & Mining of chemical and fertilizer minerals, production of salt, other mining and \\
i14.3 & quarrying n.e.c.
\end{tabular}

Based on EXIOBASE documentation. See www.exiobase.eu

incineration of waste, landfill of waste, and sanitation, remediation and similar activities.

The European Commission (2014) report by TNO on modelling resource efficiency related to buildings and infrastructure out to 2030 uses EXIOMOD to consider resource efficiency improvements in both the construction and use phases of the whole life-cycle of buildings and infrastructure in Europe. In the construction phase the analysis considers new buildings, refurbishment, and demolition including recycling, while the use phase considers both maintenance and exploitation. However, the paper does mention there are limitations of the approach including the lack of a building stock, the lack of a saturation effect on the consumption of households and general issues with how emissions and production technologies are modelled at an aggregate level within a CGE framework. To overcome some of these issues the model is coupled with both Life-Cycle Analysis (LCA) and Material Flow Analysis (MFA). The LCA analysis is undertaken and then aggregated to the level of EXIOMOD and technical coefficients in EXIOMOD are updated for different scenarios. After EXIOMOD is run the outputs are translated into physical units and then applied to an MFA analysis. Five policy scenarios are compared to a baseline run with no resource efficiency improvements and the modelling shows it is possible to reduce resource consumption and still increase GDP in the EU27, with individual countries seeing a GDP increase between $0.04 \%$ and $0.23 \%$ in 2030 under 'best practice'. They state that many of the resource improvements are win-wins where the societal benefits outweigh the costs. See Table 2 for a model comparison.

The Global Interindustry Forecasting System (GINFORS) model at GWS is a dynamic input-output simulation model which has been used in a number of studies to examine questions of resource efficiency as well as climate change. Unlike 
traditional CGE models GINFORS does not rely on long-run equilibrium of markets and is often classified as an econometric model. However, similar to other models mentioned, it is based on an environmentally extended multi-regional supply and use database of national accounts created by the World Input Output Database (WIOD) project. GINFORS level of detail is 39 world regions, 35 industries and 59 products and also includes emissions from 28 energy carriers and a resource module which considers water and land. The 12 material types are 5 different biomass, 4 fossil fuels as well as minerals construction, minerals industrial and minerals metal. ${ }^{2}$ The materials aspect is calculated by defining a specific materials intensity in local currency and constant prices attributed to a certain economic driver which is historically observed. When forecasting the driver is multiplied by its trend intensity gives the physical extraction amounts. GINFORS has been applied for a number of resource efficiency applications including Meyer et al. (2015) which linked GINFORS with a biophysical model LPJml. The results from three transition scenarios implemented showed that resource efficiency policies to reduce raw material consumption (RMC) to $5 \mathrm{t}$ per capita, combined with other environmental targets, could be achieved with increased growth and employment. Estimates for RMC for abiotic resources in 2013 were at around $14 \mathrm{t}$ per capita this a reduction of around $60 \%$ is required by the year 2050 .

E3ME model developed by Cambridge Econometrics is a macro-econometric model of the European member state economies as well as 11 other large economies and the rest of the world. The model is based upon an input-output framework which has separate modules for energy, emissions, and material demands. Again, E3ME is not based upon general equilibrium assumptions but instead the model consists of econometrically estimated behavioural relationships which can consider short and medium term economic impacts of various actors' decisions while able to capture the disequilibrium effects of issues such as long-term unemployment in the labour market. The model is based upon an EE-MRIO with 69 economic sectors for European countries and 43 sectors for the rest of the world. The calibration period is 1970-2012 with 2005 as the base year IO table. The model then solves from 1995 to 2050 . The energy module is of a top-down nature but with a bottom-up electricity representation. There are 12 different emissions modelled of which $\mathrm{CO}_{2}$ is the most detailed as it is related to energy carriers. The materials model is described in Pollitt $(2007,2008)$ and specifically considers RMC, DMI and TMR. Materials are not matched at a sectoral level but instead material intensity is able to change due to the dynamic nature of the model. The material demand equations are measured much in the same way as the economic equations with DMI per unit of output being a function of economic activity, material prices and measures of technology. Long-run price elasticities for material intensity are estimated at the EU level while short-run ones are at sectoral/country level. Feeding back into the economic module the assumption is that material consumption is all consumed as intermediate inputs (not bought by households) and a small number of sectors produce the materials. The feedback is through changes in the IO coefficients.

The E3ME model was used in the Cambridge Econometrics (2014) report for the European Commission which shows that resource productivity increases can be achieved in the EU with positive macro-economic impacts. Resource productivity is defined as GDP per unit of raw material consumption (RMC). Demand for construction

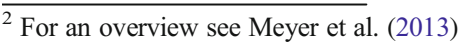


materials constitutes around $50 \%$ of all RMC. The model assumes a baseline out to 2030 for how RMC will evolve which takes the EU's climate and energy targets into account. In total RMC is expected to increase $0.7 \%$ per year until 2030 and GDP per unit of RMC increases by $0.9 \%$ per year until 2030. Metal and mineral RMC were expected to increase by $39 \%$ and $26 \%$ respectively in the baseline in 2030 . They then introduce scenarios which increase resource productivity by 1 to $3 \%$ per year. Three types of policies to improve resource productivity are market-based instruments, private funded recycling, or public funded capital investment for efficiency improvements. The E3ME results suggest that resource productivity improvements of between 2 to $2.5 \%$ can be achieved with net positive effects on GDP. However, with higher levels of ambition there are net costs productivity improvements. They suggest around 2 million extra jobs can be created with a $2 \%$ per year improvement in resource productivity.

GTEM-C developed by CSIRO in Australia is used in the GIAM framework which operates in conjunction with several other models including global climate models. There are 18 global regions included in the model and the sectoral aggregation of GIAM.GTEM-C is a total of 19 sectors including coal, gas, oil, petroleum, electricity, other mining, iron and steel, chemicals, non-metallic minerals and many others. There is no greater detail of resources in the model beyond the energy sector compared to standard GTAP modelling approaches. While the model has a unique approach in terms of energy, as well as endogenous technological progress, it does not include water, land or minerals in any greater detail. However, in a number of studies the model is linked with a variety of other models to analyse a number of national environmental factors within a consistent modelling framework. Other models include the ESM energy sector model, the LUTO model of agriculture and rural land use, the MMRF.H20 model which is a highly sectorally disaggregated CGE model split by water basin regions, and MEFISTO which is a model of materials and energy flows and integrated stocks. These models are fed from one to another in a highly complex manner. The Australian National Outlook (Hatfield-Dodds et al. 2015a) uses this combination of interlinked models, including GTEM, to analyse Australia's options in achieving sustainable prosperity out until 2050. Hatfield-Dodds et al. (2015b) use the same overall modelling framework as the national outlook in an article which shows that Australia can continue with economic growth while reducing environmental pressures.

Schandl et al. (2016) use the framework to consider the ability to decouple environmental pressure and economic growth. They combine the GIAM model, MIFESTO and the Eora MRIO model to undertake the analysis for energy use, materials use and carbon emissions for 13 major regions each with 21 sectors, 4 primary factors and 6 GHGs using the GTAP8 database. The material use data comes from the CSIRO Global Material Flow Database (Schandl et al. 2016). They implement three scenarios: a reference case, a high efficiency case and a medium case. The resource efficiency path is driven by a carbon price and also assumes that best available technologies are implemented in key resource sectors but with conservative assumptions about new technologies. The GIAM model is used as an input to create material, energy and carbon footprints using Eora by calculating a time series of year by year input-output tables to 2050 for each scenario. A satellite account for domestic materials extraction was established for different material intensity assumptions across regions. The results show that global materials extraction would grow by more than double from around 80 to 183 billion tonnes of extraction in a business as usual scenario whereas with a high 
carbon price this could be kept at 95 billion tonnes or 130 in the medium price case. At a regional level resource efficiency and the saturation effect can influence the material footprint of the larger nations which tends not to increase much beyond 2030. In general the GIAM framework would benefit from a greater disaggregation of materials used in the economic process within their economic model. It is a consideration which Schandl et al. (2016) identify as an area for improvement along with linking material, carbon and energy to capital investment and also including a better representation of resource supply limits for a variety of possible reasons i.e. physical or social. A recent publication (Hatfield-Dodds et al. 2017) assesses global resource use and greenhouse emissions to 2050; it concludes on positive impacts related to combining greenhouse gas emission abatement and resource efficiency. It is less clear, however, how the interlinkage of those models work out exectly and how the baseline case has ben set up, as it seem to miss saturation effects of economies. The latter is part of our approach.

We do not consider in detail much of the input-output modelling that has been undertaken in this area using Materials Flow Analysis (MFA). However, it is worth stating that there are a considerable number of studies using global and national inputoutput models and many of these are important in understanding how material flows can be used to calculate indicators of resource use. For instance, Wiedmann et al. (2015) on the material footprint developed countries shows the claim of such countries to have decoupled resource use from economic growth does not necessarily hold. In fact many regions have increased resource use when viewed from a consumption basis as much is imported. Giljum et al. (2015) uses an IO model from the GTAP database to calculate material footprint between the years 1997-2007 by examining worldwide materials extraction and materials embodied in consumption and trade and they state the importance of using RMC as an indicator due to leakage effects. The UNEP report uses these Material Footprint approaches in its latest report to the International Resource Panel. It is worth noting, however, that all such valuable work based on industrial ecology analysis misses an economic dimension and falls short of assessing socio-economic impacts. Our modelling framework thus aims to incorporate findings from MFA and shed light on how future resource use might evolve based on economic development pathways, and how policies might shape the decoupling processes of economies around the world.

As shown above, there is a gap in the modelling-based analysis of international policies for the circular economy. There is a clear need for developing macro-economic modelling approaches which differentiate to a greater degree between types of materials than many standard general equilibrium models (Ellen MacArthur Foundation and McKinsey Center for Business and Environment 2015), that allow comparison to other non-equilibrium models (CE and BioIS 2015; Meyer et al. 2015), and that can be employed in a stand-alone approach as well as complement other integrated modelling frameworks (Schandl et al. 2016). Our modelling approach based on the ENGAGEmaterials model aims to fill these gaps and provides a detailed and comprehensive framework towards the modelling of the circular economy.

There are also several further challenges which we do not address directly in this paper but that are relevant to mention here. Firstly, how materials interact with other resources such as land and water are also important for understanding complex nexus issues. However, here we intend to firstly increase the modelling ability of materials 


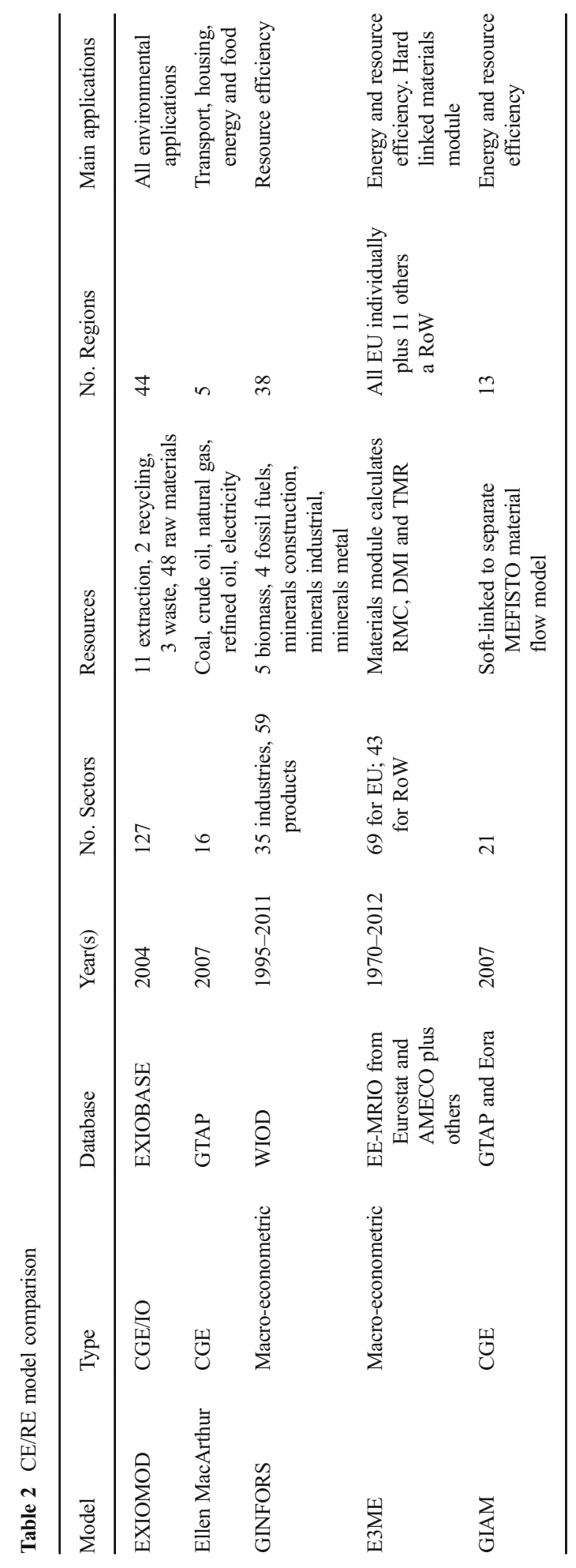


before we consider their interaction with other resources. We do not attempt to integrate all environmental concerns into one model in the manner of EXIOMOD as we believe it comes at the expense of accuracy. Another further step required will be the inclusion of endogenous innovation of resource intensive sectors in order to capture adequately the economic costs and benefits of resource efficiency policies.

\subsection{Iron and steel modelling}

Schumacher and Sands (2007) developed a detailed dynamic-recursive CGE model of the German economy from 1995 to 2050 which contains a more detailed technological representation of the iron and steel sector as an example of how to improve realism of production in energy-intensive industries. In particular they use a logit nesting approach to distinguish between the technologies of Basic Oxygen Furnace (BOF), Electric Arc Furnace (EAF) and a direction reduction process which are all utilised to create crude steel production with a low elasticity between these. Both the BOF and EAF processes, which are considered primary and secondary production routes respectively, have both standard and advanced possibilities too, which are substitutable at a higher elasticity. They then introduce a set of $\mathrm{CO}_{2}$ price scenarios for this new technology based approach and then compare the results against an aggregate standard Constant Elastcity of Substiution (CES) scenario. A conclusion is drawn that there is significant importance of technology-specific effects in terms of climate policies relating to differences between changes in process and in fuel input structures that would not be captured by a more general top-down CGE approach.

Yamazaki (2011) uses a single-region CGE model for Japan in 2005 which disaggregates the steel sector into a variety of technologies to allow for analysis of the effects of $\mathrm{CO}_{2}$ trading on scrap steel production in Japan. There are 38 production sectors, 53 products, 3 final demand sectors and international trade. The model distinguishes between Blast Furnace-Basic Oxygen Furnace (BF-BOF) and Electric Arc Furnace (EAF), a number of different steel products e.g. cast and forged steel products, and also between three types of scrap steel: home scrap from the steel manufacturing industry, industrial scrap from drilled or cut metal from manufacturing, and obsolete scrap which is collected. Japanese national economic and physical data on iron and steel is fairly detailed and so allows for such an analysis including which sectors to allocate tonnes of scrap steel supply and demand in the base year. The introduction of emissions trading leads to increased demand for EAF products but to an overall decline in the amount of scrap steel used due to the shrinking economy when undertaking emissions trading.

The single example of a global iron and steel economic model appears to be a conference paper from Zhou et al. (2014) which created a Multi-Regional Input-Output (MRIO) model based upon GTAP-7. Here the iron and steel production sector (GTAP i_s) is disaggregated into three types: pig iron, blast furnace, and electric arc furnace. They also provide more detail the iron ore extraction sector by separating it from the 'other mining' sector (GTAP omn). And finally recycling is considered by disaggregating the Manufactures nec. Sector (GTAP omf) into three types: Steel scraps recycling, other recycling, and other manufacturing. The authors state that for four countries (Japan, China, Australia, USA) they used national accounts to disaggregate intermediate inputs, final demands and outputs. They use the data World Steel Statistical Yearbook and Global Trade Atlas Database for other regions. Results are provided 
for primary resource us and carbon emissions, resource efficiency and carbon intensity, and for international trade. However, the MRIO model does not consider prices therefore it is unable to incorporate a number of policies.

Moving beyond purely macro-economic models there are industrial ecology studies such as that of Pauliuk et al. (2013a, b) on the 'scrap steel age' and in-use stocks of iron that can be extremely useful in helping to frame the sorts of scenarios which we intend on implementing using the ENGAGE-materials model focused on differentiating between primary and secondary steel and possible saturation effects.

Importantly the ENGAGE-materials model described in Section 3 below will allow for the asssesment of the macro-economic impacts of a variety of future fiscal and environmental steel policies and technological developments.

\section{Methodology}

Here we outline the development of the UCL Environmental Global Applied General Equilibrium (ENGAGE) model further with respect to the inclusion of materials and minerals which will allow a detailed analysis of resource efficiency and circular economy scenarios. While many other macro-economic modelling approaches have focussed on energy, land and water i.e. OECD ENV-Linkages model, we believe that materials are an under-developed area in the macro-economic modelling framework at both national and global levels. We believe there are three main areas which could be developed further within the typical global CGE framework: extraction, industry and recycling.

The majority of Social Accounting Matrixes (SAMs) tend to have highly aggregated materials extraction sectors i.e. there are only 4 GTAP extraction sectors, and therefore the accompanying CGE models lack the relevant detail for such policy analysis. Also, the production sectors of many important metals and minerals are combined together into a single industry, and often recycling is not explicitly represented meaning any analysis on policies related to these sectors is almost impossible. Therefore we propose as a first step a greater sectoral disaggregation in these three key areas (extraction, industry and recycling) in order to allow a sufficient level of detail to properly capture changes and innovation.

In section 3.1 we present a brief overview of our newly developed global CGE model ENGAGE. We then give details of the planned model disaggregation with regards to the extraction in section 3.2 and primary/secondary production sectors as well as discussing the data required to implement such and discuss how production structures of specific materials sectors are developed to more realistically represent firm technology choices in section 3.3.

\subsection{General model structure and data}

The UCL ENGAGE-materials model is a special version of the UCL ENGAGE model which is a standard multi-sectoral, multi-region, dynamic computable general equilibrium model. ENGAGE is based upon standard general equilibrium assumptions such a market clearance, zero profits, and utility maximisation/cost minimisation of representative agents. All industries are modelled through a representative firm, which 
maximizes its profits in perfectly competitive markets. The production functions of each economic sector to create a level of sectoral output are specified using a series of nested constant elasticity of substitution (CES) functions. Domestic and foreign inputs are not perfect substitutes and therefore are modelled using the "Armington assumption", which accounts for product heterogeneity between different world regions. A representative consumer in each region receives household income, defined as the service value of national primary factors. The national income is allocated between aggregate household consumption, public consumption and savings.

The UCL ENGAGE model is based upon the GTAP-9 database with a base year of 2007. The ENGAGE model is written in GAMS and based upon the GTAP9inGAMS model in MPSGE developed by Lanz and Rutherford (2016) and the model runs in a recursive-dynamic setting from 2007 to 2030. Production in each sector is derived using a series of nested CES function where at the top level intermediate inputs combine with a capital-labour-energy (KLE) aggregate using a Leontief assumption.

The ENGAGE model can be used to implement counterfactual analysis of changes in relative prices of intermediate inputs and/or factors of production e.g. through changes in tax rates, and captures the direct and indirect effects of such price changes on other sectors and other regions. The GTAP database, and CGE models in general, are useful tools for short to medium term economic analysis where the underlying structure of the economy does not deviate far from the base year e.g. an election cycle or a couple of decades. However, undertaking medium and long-term economic analysis will require updates of parameters throughout the model's time horizon and as such models generally find it necessary to incorporate technological change and new products. While we admit this is not yet sufficiently addressed in our model as of now and a general challenge for most (if not all) macro-economic models, we intend to do such updates of parameters in due time. A first step we incorporate in this paper the saturation effect as it has been analysed by historical time series (Bleischwitz and Nechifor 2016).

The main data source, in addition to GTAP, to construct the ENGAGE-materials database and model is the EXIOBASE2 dataset (Tukker et al. 2014) for 2007. ${ }^{3}$ The EXIOBASE input-output database is used to split out the shares of the various extraction, industrial and recycling sectors which will require greater disaggregation within the GTAP database. In general we use EXIOBASE as the underlying inputs throughout the following analysis due to the level of sectoral detail (see Table 1). We therefore mapped the 129 EXIOBASE sectors to the 57 GTAP sectors. However, there are instances where the underlying EXIOBASE data does not appear to match. We give further detail on specific EXIOBASE and other data inputs below.

In addition to EXIOBASE we combine the necessary physical and price commodity data from a number of key materials and resource datasets such as UN COMTRADE, FAOSTAT, United States Geological Survey (USGS) Minerals Yearbook, World Steel Association as well as a variety of national accounts datasets.

In the first instance we plan to make developments to the extraction, industrial and recycling sectors of the ENGAGE-materials model in relation to iron and steel. The material we focus on specifically in this analysis is iron ore given it's relative importance as intermediate input in the global supply chain and relevance to the EU and

\footnotetext{
${ }^{3}$ www.exiobase.eu
} 


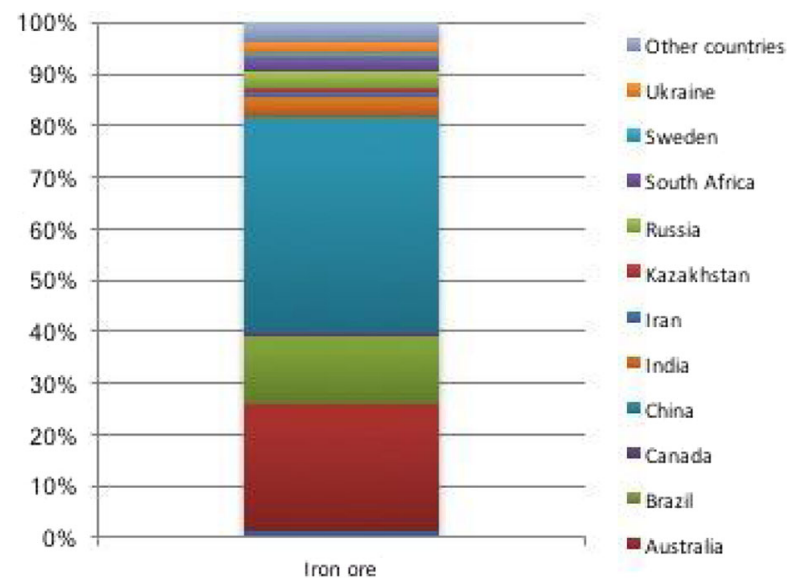

Fig. 1 Iron ore production by region (2007). Source: USGS

China (Fig. 1). The largest producer of iron ore is China which accounts for just over $40 \%$ of global production. China is then followed by Australia $(25 \%)$ and Brazil $(12.5 \%)$ and then by India (4\%) and Russia (3\%) respectively and these countries combined produce over $80 \%$ of iron ore (USGS 2015). However, it is our intention to extend the analysis to other materails where data sources are more readily available.

Key regions which produce, consume, export and import these commodities are included as separate regions in ENGAGE-materials to the best of our abilities given data constrains. The proposed regional disaggregation of the ENGAGE-materials model reflects these considerations and includes 17 regions (Table 3 ). ${ }^{4}$

\subsection{Extraction}

Firstly, we disaggregate the single GTAP 'other mining' sector (OMN) in order to capture the flows of different key materials throughout the world economy. Mining and extraction of coal, gas and oil are all individual sectors in GTAP. However, this is not the case for the extraction of other materials and minerals which are all lumped together, many of which are important individually for analysis of resource efficiency and the circular economy - perhaps explaining the lack of modelling of such issues using global CGE models. The single 'other mining' sector includes mining of metal ores, uranium, gems, other mining and quarrying. Therefore current analyses based upon the standard GTAP database are only able to apply counterfactual analyses to the extraction of all metals together while clearly there are distinct production processes and government policies. Clearly if we wish to trace the flow of such materials throughout the economy, and through global trade, then further disaggregation is required. This disaggregation will then allow analysis of price changes, policy interventions and technology innovations of these specific material extraction sectors for each individual region within our CGE framework.

\footnotetext{
${ }^{4}$ We have distinguished between Western Europe and Eastern Europe as well as having Germany as a single region. However, we may alter this regional aggregation for Europe depending upon questions we pose and further data availaibility.
} 
Table 3 ENGAGE-materials regions

\begin{tabular}{ll}
\hline Regions (17) & \\
\hline China & CHN \\
Japan & JPN \\
India & IND \\
USA & USA \\
Russia & RUS \\
South Korea & KOR \\
Brazil & BRA \\
Mexico & MEX \\
Canada & CAN \\
Australia & ANZ \\
Indonesia & IDN \\
Germany & DEU \\
Western Europe & WEU \\
Eastern Europe & EEU \\
Asia and Oceania & ASO \\
Latin America & LAM \\
Africa & AFR \\
\hline
\end{tabular}

Therefore we disaggregate the material extraction sector 'other mining' (GTAP $\mathrm{OMN}$ ) in each region in order to capture the flows of different key materials throughout the world economy. This is necessary for industry-focussed analysis on resource efficiency and a circular economy using a life-cycle approach of materials. Using shares and cost structures from the EXIOBASE dataset (Tukker et al. 2014) as well as a variety of national accounts databases, and employing the SPLITCOM programme, we split the single 'other mining' sector into three separate sectors: (1) mining of iron ore, (2) non-ferrous mining and (3) other mining. ${ }^{5}$ Totals were kept consistent with the aggregate OMN sector.

In terms of physical data, there appears to be consistency between EXIOBASE and estimates taken from USGS, which is most likely due to the data coming from the same initial source. However, the monetary data from EXIOBASE appears somewhat inconsistent for some large mining producers compared to independent estimates taken from other sources such as national accounts. Therefore we were required to undertake an independent re-estimation of the OMN split initially undertaken using EXIOBASE.

Where detailed national accounts data on specific mining sectors is available then we utilise these to split these regions and detail the relevant size of the iron mining sector, the iron ore mining sector's cost structure, and to what other economic sectors iron ore is sold. For Australia, Brazil and China we used their national 2007 input output data which sperately details the iron ore mining sector as a single sector. We were only able to obtain data for India from 2004 and so we use these shares to split Indian iron ore mining in our database. The USA national data has iron ore mining aggregated together with other metals such as gold and silver. Canadian data sources

\footnotetext{
${ }^{5}$ More disaggregated splits are currently faced with data restrictions though may become possible over time.
} 
provided us with the overall size of the iron ore mining in relation to other mining but a specific input output table was unavailable and therefore the cost structure and output structure were assumed from EXIOBASE.

For Russia we were unable to obtain national accounting data and therefore we calculate the Russian shares from a bottom-up method using average world price derived from other regions. All other regions in the model are considered small iron ore producers and as such we use the EXIOBASE data source for splitting the original OMN sector.

The EXIOBASE database is clearly an important addition to the production of global environmentally extended input-output datasets which can be utilised for research and policy analysis. However, we urge caution when utilising the database to undertake and suggest diving deeper into the numbers of specific resources and sectors. For instance, the overall sectoral size of iron ore mining in China from EXIOBASE, shown in Table 4, is much smaller than the national statistics provided. Therefore carrying out any analysis of the iron ore sector in a model which utilises EXIOBASE as the underlying database, such as EXIOMOD, would severly under-estimate the impacts of policies implemented for that sector.

\subsection{Primary and secondary production}

The recycling and reuse of scrap metals is an integral element of any circular economy package. However, most macro-economic models have little or no detail with regards to recycling of specific materials and there are no single secondary production or recycling sectors within the GTAP database. Therefore, we further enhanced the ENGAGEmaterials database to consider such secondary production and recycling within the economy. Our aim is to model the supply of secondary materials which could come from sources such as reuse, recycling and recovery from anthropogenic stocks. The production of secondary materials may well have an input structure different to that of the primary sector due to process innovations and efficiency improvements. Again we employ a methodology here for the production of scrap steel. Other secondary material productions sectors may be possible to implement in a similar manner in future work e.g. non-ferrous metals such as copper and aluminium, However, here we have undertaken work for steel only given data restrictions and an initial attempt to consider the process before we undertake it for metals which may be more complicated.

Table 4 EXIOBASE vs ENGAGE-materials shares of iron ore mining

\begin{tabular}{|c|c|c|c|c|c|c|}
\hline \multirow[t]{2}{*}{ Source } & \multirow[t]{2}{*}{ Country } & \multicolumn{2}{|l|}{ Iron ore } & \multicolumn{2}{|l|}{ Other mining } & \multirow{2}{*}{$\begin{array}{l}\text { GTAP OMN } \\
\text { TVOM \$m } 2007\end{array}$} \\
\hline & & EXIOBASE & ENGAGE & EXIOBASE & ENGAGE & \\
\hline National Accounts 2007 & Australia & $4 \%$ & $39 \%$ & $96 \%$ & $61 \%$ & 53,609 \\
\hline National Accounts 2005 & Brazil & $45 \%$ & $66 \%$ & $55 \%$ & $34 \%$ & 32,390 \\
\hline National Accounts 2007 & Canada & $2 \%$ & $9 \%$ & $99 \%$ & $91 \%$ & 19,065 \\
\hline National Accounts 2007 & China & $7 \%$ & $36 \%$ & $93 \%$ & $64 \%$ & 121,248 \\
\hline National Accounts 2005 & India & $26 \%$ & $25 \%$ & $74 \%$ & $75 \%$ & 16,365 \\
\hline USGS and price estimates & Russia & $2 \%$ & $44 \%$ & $98 \%$ & $56 \%$ & 15,576 \\
\hline National Accounts 2007 & USA & $0.3 \%$ & $5 \%$ & $99.7 \%$ & $95 \%$ & 48,041 \\
\hline
\end{tabular}


We take several steps in order to further develop the capability to consider recycling and scrap sectors. In our modelling framework the original GTAP production sector 'Iron and Steel' (I_M) is further disaggregated to distinguish between primary and secondary production technologies. Then for secondary production we distinguish between two types: the treatment of secondary steel (which utilises recycling services) and reprocessing of secondary steel into new steel which produces the final output. While primary steel production is based on the Oxygen Blast Furnace technology, secondary steel production uses the Electric Arc Furnace technology and both technologies are explicitly modelled in our framework. The World Steel Association data was used for the calibration of primary and secondary production levels.

It was initially unclear whether the production of secondary production in GTAP takes place in the 'iron and steel' sector or in the 'other manufacturing' sector (which includes recycling within it). In fact, all types of recycling in the economy are aggregated together within 'other manufacturing'. Below we outline the indentification and methodology we employed to distinguish secondary production and the role that recycling plays within it.

A list of the final proposed 34 sectors in our CGE model on resource efficiency and the circular economy are given in Table 5 and further details of the split procedure are provided below.

Table 5 ENGAGE-materials sectors

\begin{tabular}{|c|c|c|c|}
\hline Iron and steel related sectors (15) & & Energy related (13) & \\
\hline Iron mining & i_m & Coal & coa \\
\hline Non-ferrous mining & $\mathrm{n} \_\mathrm{m}$ & Crude oil & oil \\
\hline Other minerals mining & o_m & Gas & gas \\
\hline Iron and steel primary production & isp & Petroleum \& Coke & p_c \\
\hline Re-processing of secondary steel into new steel & rss & Transmission and distribution & tnd \\
\hline Secondary steel for treatment & sst & Nuclear power & nup \\
\hline Non-ferrous metals & $\mathrm{nfm}$ & Coal-fired power & $\mathrm{cfp}$ \\
\hline Non-metallic minerals & $\mathrm{nmm}$ & Gas-fired power & gfp \\
\hline Metal products & mtp & Wind power & wip \\
\hline Motor vehicles and transport equipment & mvt & Hydro power & hyp \\
\hline Electronic equipment & ele & Solar power & sop \\
\hline Machinery and other equipment & mae & Oil-fired power & ofp \\
\hline Recycling & rcy & Other power & otp \\
\hline Construction & cns & & \\
\hline Transport & tra & & \\
\hline \multicolumn{4}{|l|}{ Other sectors (6) } \\
\hline Agriculture and food & agr & & \\
\hline Wood products & wop & & \\
\hline Paper products & ppp & & \\
\hline Chemical products & crp & & \\
\hline Other manufacture & oma & & \\
\hline Services & ser & & \\
\hline
\end{tabular}


Initially, using EXIOBASE, we split the aggregate iron and steel production sector (I_S in GTAP) into two - Iron and Steel Primary (ISP) and Iron and Steel Secondary (ISS) as this matches the level of sectoral detail provided in the EXIOBASE IO tables. Examples of the cost structure of ISP are shown in Table 6. However, in the EXIOBASE documentation on physical supply and use tables (CREEA 2012) it states that there are two processes within a waste treatment service entitled 'Secondary steel for treatment, Re-processing of secondary steel into new steel'. There are two clearly distinct processes captured here under one heading: one which treats the steel (and importantly uses recycling sector as an intermediate input) and another which converts the treated steel into an end product which is the output of the manufacturing sector. Therefore to capture these distinct processes we disaggregate the newly created secondary steel production sector ISS further, using some technological and economic assumptions.

We create two new sectors: (1) secondary steel for treatment (SST) - that's inputs are only recycling and the value added and other intermediate inputs to balance the sector (see Table 7), and (2) reprocessing of secondary steel (RSS) - which is where we model the production of secondary steel through the EAF method to create new steel which is purchased by other sectors (see Table 8). All own-demand in the aggregate ISS sector is considered the output of the SST activity All recycling costs of ISS are attributed to SST. In order not to have to modify the underlying GTAP structure, we make a simplifying assumption that the value of scrap is assumed to be the value of capital in the SST sector i.e. the capital investment in steel treatment reflect the shadow value of steel scrap. The total output of the SST sector is then sold on directly to the RSS sector. The RSS cost structure is defined by EXIOBASE and will be similar to that of the ISS aggregate but with lower capital share.

We also altered the production structure of these newly constructed primary and secondary production sectors in order to capture a more realistic production process in

Table 6 Main inputs to ISP cost structure for Australia, China and USA

\begin{tabular}{llll}
\hline & Australia & China & USA \\
\hline i_m & $1.4 \%$ & $10.5 \%$ & $0.5 \%$ \\
n_m & $6.6 \%$ & $9.4 \%$ & $2.7 \%$ \\
o_m & $13.4 \%$ & $2.0 \%$ & $0.9 \%$ \\
p_c & $4.1 \%$ & $7.2 \%$ & $3.6 \%$ \\
nmm & $0.5 \%$ & $2.5 \%$ & $2.3 \%$ \\
isp & $14.6 \%$ & $24.5 \%$ & $9.6 \%$ \\
rss & $3.3 \%$ & $3.1 \%$ & $6.0 \%$ \\
ome & $0.6 \%$ & $4.3 \%$ & $6.0 \%$ \\
ely & $2.2 \%$ & $2.5 \%$ & $3.1 \%$ \\
trd & $3.6 \%$ & $2.2 \%$ & $8.3 \%$ \\
otp & $7.7 \%$ & $1.4 \%$ & $4.0 \%$ \\
obs & $4.7 \%$ & $0.7 \%$ & $4.4 \%$ \\
All other inputs & $11.5 \%$ & $11.7 \%$ & $13.3 \%$ \\
Labor & $15 \%$ & $8 \%$ & $27 \%$ \\
Capital & $11 \%$ & $9 \%$ & $8 \%$ \\
Total & $100 \%$ & $100 \%$ & $100 \%$ \\
\hline
\end{tabular}


Table 7 Main inputs to SST cost structure for Australia, China and USA

\begin{tabular}{llll}
\hline & Australia & China & USA \\
\hline Rcy & $1.6 \%$ & $24 \%$ & $0.01 \%$ \\
Scrap (capital) & $98.6 \%$ & $76.0 \%$ & $99.98 \%$ \\
Total & $100 \%$ & $100 \%$ & $100 \%$ \\
\hline
\end{tabular}

these sectors. Figure 2 shows the nested production structures for these three sectors which capture greater technological detail than previously where only one single iron and steel production sector existed.

In the primary steel (ISP) sector the pig iron composite is created from a Leontief input of ISP (i.e. purchases from itself), iron ore, and coke. This structure was taken to represent the technological process of primary production similar to Schumacher and Sands (2007). The re-processed steel (RSS) sector has electricity as a distinct input at the top level of the production function in order to replicate the production process used in electric arc furnace. The secondary steel for treatment (SST) sector combines with ISP in the second nest of the RSS sector with a very low elasticity of substitution between them. The SST sector only has one nesting level which has scrap, recycling, value added and other intermediates. Substitution of steel coming from ISP and RSS are industry specific. The changes made in our methodology now allow for opportunities to model policies and scenarios for scrap availability e.g. boost in overall or sector-specific recycling rates/quotas.

\section{Results}

In Section 3 we outlined a variety of ways in which we constructed the data and developed the modelling of iron and steel within the context of resource efficiency and

Table 8 Main inputs to RSS cost structure for Australia, China and USA

\begin{tabular}{llll}
\hline & Australia & China & USA \\
\hline $\mathrm{n} \_\mathrm{m}$ & $6.1 \%$ & $9.8 \%$ & $0.9 \%$ \\
$\mathrm{o} \_\mathrm{m}$ & $12.2 \%$ & $1.6 \%$ & $0.2 \%$ \\
$\mathrm{p} \_\mathrm{c}$ & $3.2 \%$ & $1.9 \%$ & $0.9 \%$ \\
$\mathrm{nmm}$ & $0.4 \%$ & $2.7 \%$ & $0.6 \%$ \\
isp & $13.4 \%$ & $27.9 \%$ & $16.6 \%$ \\
sst & $3.0 \%$ & $3.5 \%$ & $9.0 \%$ \\
ome & $0.3 \%$ & $4.7 \%$ & $10.2 \%$ \\
ely & $9.3 \%$ & $14.2 \%$ & $3.9 \%$ \\
trd & $6.1 \%$ & $3.0 \%$ & $8.3 \%$ \\
otp & $10.3 \%$ & $1.9 \%$ & $5.7 \%$ \\
obs & $4.5 \%$ & $0.8 \%$ & $4.5 \%$ \\
All other inputs & $11.1 \%$ & $11.3 \%$ & $12.6 \%$ \\
Labor & $15 \%$ & $10 \%$ & $27 \%$ \\
Capital & $5 \%$ & $7 \%$ & $0 \%$ \\
Total & $100 \%$ & $100 \%$ & $100 \%$ \\
\hline
\end{tabular}



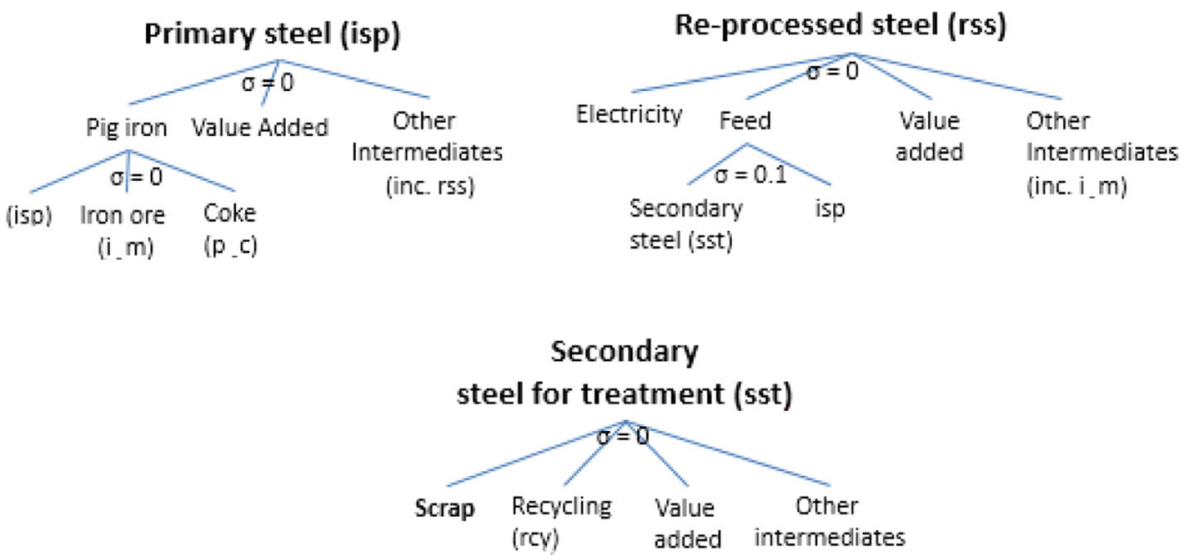

Fig. 2 Production structure of ISP, RSS and SST sectors

the circular economy. The disaggregation of these new resource sectors on extraction, industry and recycling, combined with the regional aggregation that highlights resource producers and consumers, allows for a model to consider the global direct and indirect effects of policies, shocks and futures which fall on resource-intensive sectors.

We now attempt to provide an example of how the model can be employed to assess steel specific circular economy policies. For the purposes of this paper we have implemented an initial baseline and a scenario using the newly constructed database and model structure. Here we provide a sample of the initial results. The model baseline is given in Figs. 3a, b. Figure 3a shows the increase in global steel production and how this is split between primary and secondary production. In the baseline we align the regional GDP in ENGAGE to the SSP2 estimates by changing exogenously total factor productivity in each region. As a result resource extraction is linked to regional economic growth. Overall steel production in ENGAGE increases by about $23 \%$ over the time period to 2030. This is somewhat short of the $30 \%$ from the World Steel Association (2015) global steel outlook. ${ }^{6}$ This difference is partially explained by our assumptions around the size of the saturation effect in China. Indeed, we assume that the iron and steel demand in China starts a gradual and continuous decline at around 2015 (Fig. 3b) as a per capita income value of about US \$12,000 has been reached that had been decisive for a saturation across other economies (Bleischwitz and Nechifor 2016).

The regional iron and steel production baseline (Fig. 3b) shows the extent of the saturation effect in China (Bleischwitz and Nechifor 2016) - an analysis of which does not yet seem to be part of e.g. UNEPs International Resource Panel trends analysis (UNEP 2017; Hatfield-Dodds et al. 2017: 408). We also seek to incorporate further findings on the saturation effect, i.e. countries becoming less material-intensive as they move through stages of development, along with a general decoupling of resource use and GDP in our modelling attempts. The baseline production also appears to roughly match the World Steel Association (2015) estimations with India and Asia \& Oceania increasing their production at a faster than most regions.

\footnotetext{
${ }^{6}$ Our exogenous assumption of SSP2 growth may well affect how country specific and the overall growth which occurs compared to other studies. We intend to consider a comparison with other such estimates in further work.
} 

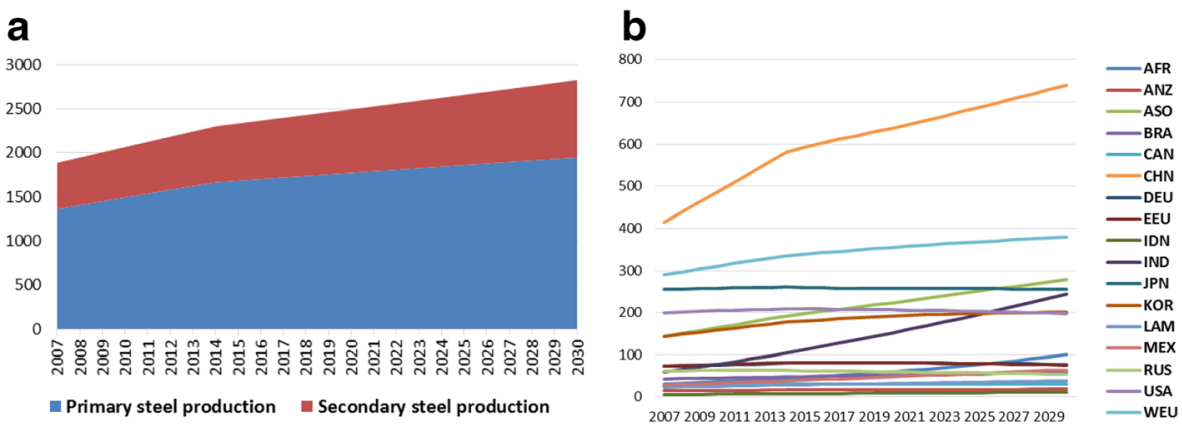

Fig. 3 a Global steel production to 2030. b Regional steel production to 2030. Both Figures are in million US\$

Figure 4 shows the regional shares in the baseline of primary vs. secondary production in 2030 . Almost $85 \%$ of Chinese production comes from primary steel production showing that there is considerable potential to implement and gain improvements from circular economy policies aimed at increasing scrap rates. Mexico, Latin America and the USA all produce around $40 \%$ of their steel through secondary production and the two regions with the highest secondary production are Indonesia and Asia \& Oceania which produce around $50 \%$ and $65 \%$ of their steel from secondary production, respectively.

For the purposes of this paper we also have implemented a policy scenario which doubles the scrap availability in all regions by 2030 , starting gradually from 2018 . This policy scenario aims to boost secondary production of steel and reduce resource and energy use in the steel industry. Indeed such policies will be refined throughout in future specific analysis.

The results in Table 9 show that doubling of scrap availability leads to secondary steel production increasing by around $7 \%$ in 2030 compared to the baseline. Global primary steel production reduces somewhat as there is a shift towards secondary production, however, there is an overall increase in total production of just under $2 \%$ globally. It appears that the rigidities in the production processes modelled here are causing the fact that substantial increases in scrap availability may only lead to relatively small improvements in overall economic terms; this is up for further analysis over the coming months through sensitivity analysis of both the elasticity parameters and model structure.

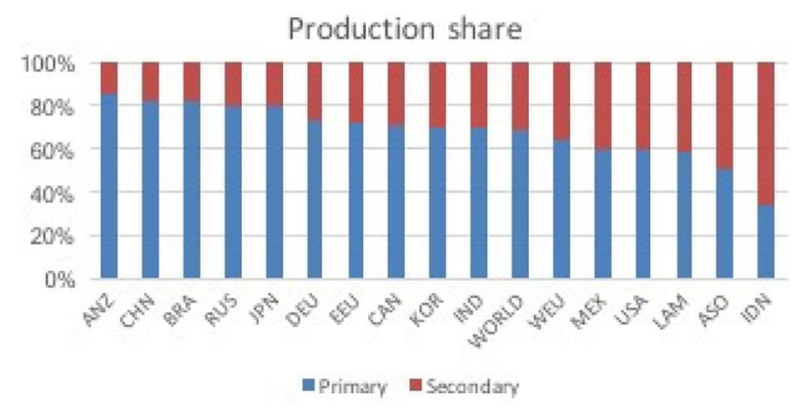

Fig. 4 Production share in Baseline (2030) 


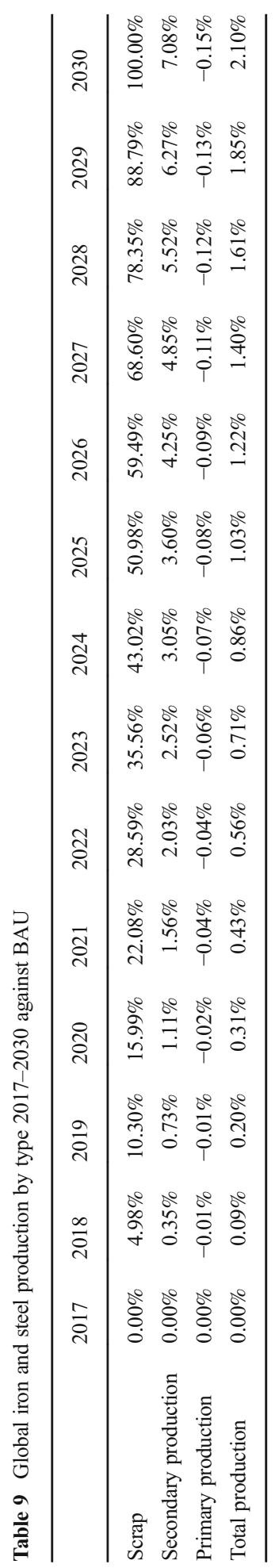


Global and regional GDP changes are given below in Fig. 5a and shows that the majority of regions benefit from the exogenous increase to scrap availability. Certain regions experience large increases in secondary production, for instance ANZ increases by $27 \%$ by 2030 . Those regions which are most negatively affected are South Korea and Africa which see reduction in GDP of $0.7 \%$ and $0.6 \%$ respectively in 2030 against the baseline. There is also a small reduction of GDP in Asia and Oceania region as well as Mexico. It appears that these four regions (AFR, ASO, MEX, KOR) lose out from a reduction in their primary production which outweighs the benefits of any increases in secondary production. The only region to see a fall in both primary and secondary is ASO. All other regions incur increases in both primary and secondary steel production.

The environmental effect of doubling of the scrap sector is given in Fig. 6 and shows an overall reduction in the $\mathrm{CO}_{2}$ emissions from fossil producing sectors. In particular oil production decreases most given its input into primary steel production - further analysis is required here. Other decreases in coal and gas are partially offset by increased use of electricity in secondary production and associated rise in fossil fuel electricity production.

\section{Conclusions}

The majority of global environmental macro-economic models have focussed on energy and related GHG emissions; to a lesser extend water, food and land have been covered, but there has been a derth of studies concerned with resource efficiency and the circular economy. The few recent modelling studies detailed in Section 2 have been key to recent analysis of resource efficiency and circular economy agendas, however, there are wide ranging approaches and levels of detail when it comes to the modelling tools employed to tackle such questions. Many current models lack detail on specific resource extraction sectors and downstream resource-intensive sectors. In particular there is a lack of materials-specific sectors in macro-economic models which allow full consideration of the circular economy. Extraction, primary production, secondary production, and recycling are all required areas that are underdeveloped in almost all the global modelling approaches, except EXIOBASE which does include two recycling sectors (metals and non-metals) and several waste sectors. However, there is little published work on these areas using the EXIOMOD model and initial anaylsis of the underlying database suggests underestimation of the size of key materials sectors which

a

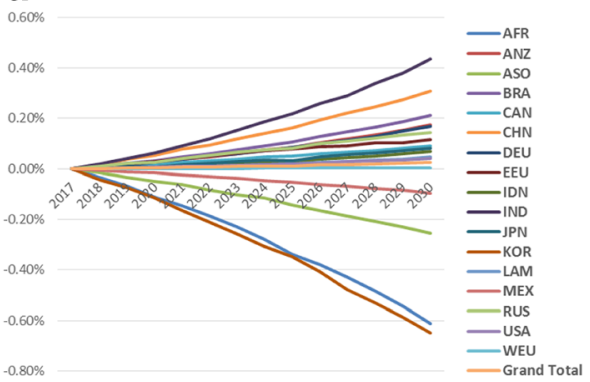

b

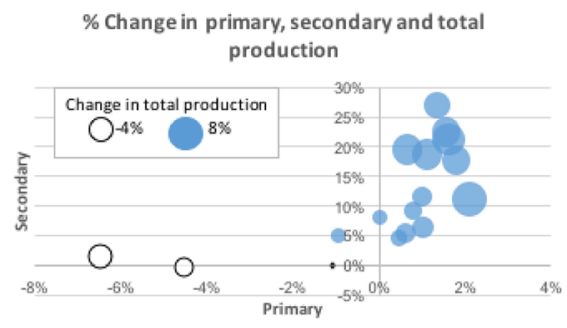

Fig. 5 a Regional GDP \% change against BAU. b Primary, secondary and total production \%. (2030) 


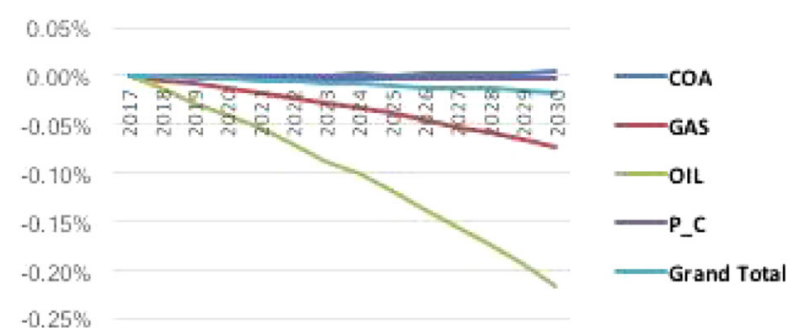

Fig. 6 Emissions of fossil fuel sectors \% change against BAU

would lead to dubious model results. We therefore see a significant opportunity to consider materials further within macro-economic modelling.

In Section 3 we described the development of a comprehensive database and modelling tool, UCL ENGAGE-materials, which can address both upstream and downstream impacts of resource efficiency and circular economy policy implications. Utilising a global database allows for focus on the global trade aspect of changes to material flows and, in particular, how these changes affect the commodity trade between major producing and consuming regions. The model development in the areas of extraction, industry and recycling combined with unique resource sector-specific production structures creates a CGE modelling tool which can specifically consider questions on resource efficiency and circular economy policies at the appropriate level of detail. We apply this model to steel production and consider this a novel contribution too.

Initial results to explore potential policy implementations show that there will be positive economic and environmental effects of policies which increase the amount of scrap availability globally. Doubling scrap availability in each region between 2017 and 2030 would lead to an increase in secondary production of $7 \%$ globally and an overall increase in global steel output of around 2\%. Regional differences are observed depending upon initial inputs and cost structure as well as the technological production structures. The overall GDP effects are relatively small and most are positive. We plan to analyse the wider sectoral impacts of such policies in more detail. Further work on sensitivity analysis is required to test model responsiveness as we have begun with a very ridged production structure for secondary steel production. There are also small reductions in emissions related to a shift in production from more emissions-intensive primary production towards cleaner secondary production.

Future research will utilise this newly developed tool to assess scenarios, policies and narratives which are of importance to improving circular economy understanding at a macro-economic and sectoral level for the major producer and consumer regions. Future analysis would focus on developing a more detailed baseline scenario which incorporates saturation effects on different economies. Future work will focus on potential price shocks as well as considering more elaborate policies directed towards circular economy related to China and the global steel industry. In this regard, we will also look at the impact country-specific scrap steel targets would have on EU-China trade patterns e.g. doubling scrap in China by 2050. There is also an opportunity to further consider the potential double environmental benefits of increased secondary steel production which also uses low-carbon electricity as a significant input. We also plan to use the model to undertake analyses of material footprints and environmental indicators. 
Acknowledgements This paper acknowledges funding through the ESRC et al. funded SINCERE project (ES/L015838/1) as well as the EU-funded MICA project (Grant Agreement no. 689468). The authors are also grateful for discussions with Paul Welfens, Rene Kemp and Geng Yong.

Open Access This article is distributed under the terms of the Creative Commons Attribution 4.0 International License (http://creativecommons.org/licenses/by/4.0/), which permits unrestricted use, distribution, and reproduction in any medium, provided you give appropriate credit to the original author(s) and the source, provide a link to the Creative Commons license, and indicate if changes were made.

\section{References}

Bleischwitz, Nechifor (2016) Extrapolation or saturation - an exploration into growth patterns, development stages and decoupling. Centre Cournot Prisme 34

Bohringer C, Rutherford T (2015) The circular economy - an economic impact assessment. Report to SUNIZA. Available from: https://sunstiftungsfonds.files.wordpress.com/2015/06/report-circular-economy.pdf.

Cambridge Econometrics (2014) Study on modelling of the economic and environmental impacts of raw material consumption, European Commission Technical Report 2014-2478.

CE and BioIS (2015) Study on modelling of the economic and environmental impacts of raw material consumption. European Commission, Brussels

Chatham House (2012) Resources Futures. Chatham House, London

CREEA (2012) Recommendation of terminology, classification, framework of waste accountsand MFA, and data collection guideline

Ellen MacArthur Foundation and McKinsey Center for Business and Environment (2015) Growth within: a circular economy vision for a competitive Europe. Ellen MacArthur Foundation, Cowes

European Commission (2014) Assessment of scenarios and options towards a resource efficient Europe: an analysis for the European built environment. European Commission. Available from: http://ec.europa.eu/ environment/enveco/resource_efficiency/pdf/TP_report.pdf

European Commission (2015) Closing the loop - An EU action plan for the Circular Economy. Brussels, 2.12.2015 COM(2015) 614 final

Giljum S, Bruckner M, Martinez A (2015) Material footprint assessment in a global input-output framework. J Ind Ecol 19(5):792-804

Hatfield-Dodds S, Schandl H, Adams PD, Baynes TM, Brinsmead TS, Bryan BA, Chiew FHS, Graham PW, Harwood MGT, McCallum R, McCrea R, McKellar LE, Newth D, Nolan M, Prosser I, Wonhas A (2015a) Australia is? free to choose? economic growth and falling environmental pressures. Nature 527 (7576):49-53

Hatfield-Dodds S, Schandl H et al (2015b) Australia is 'free to choose' economic growth and falling environmental pressures. Nature. doi: 10.1038/nature16065

Hatfield-Dodds S et al (2017) Assessing global resource use and greenhouse emissions to 2050, with ambitious resource efficiency and climate mitigation policies. J Clean Prod 144:403-414

Lanz B, Rutherford TF (2016) GTAPINGAMS version 9: Multiregional and small open economy models with alternative demand systems. University of Neuchatel, Institute of Economic Research, Irene, working paper 16-08, 1-73.

Meyer M, Distelkamp M, Ahlert G, Meyer B (2013) Macroeconomic modelling of the global economyenergy-environment nexus: an overview of recent advancements of the dynamic simulation model GINFORS. Discussion Paper, GWS, 2013/5

Meyer B, Distelkamp M, Beringer T (2015) Report about integrated scenario interpretation: GINFORS/LPJml results. Deliverable D3.7a for the FP7 project POLFREE (Policy Options for a Resource Efficient Europe)

Pauliuk S, Milford R, Muller D, Allwood J (2013a) The steel scrap age. Environ Sci Technol 47(2013):34483454

Pauliuk et al (2013b) Steel all over the world: estimating in-use stocks of iron for 200 countries. Resour Conserv Recycl 71(2013):22-30

Pollitt H (2007) Extending E3ME to include analysis of material flows, a scoping WP3 report for the AngloGerman foundation. Cambridge Econometrics 
Pollitt H (2008) Combining economic and material flows analysis at the sectoral level: development of the E3ME model and application in the MATISSE case studies. MATISSE Project Deliverable 8.6.1 for the European Commission, DG Research, April

Schandl H, Hatfield-Dodds S et al (2016) Decoupling global environmental pressure and economic growth: scenarios for energy use, materials use and carbon emissions. J Clean Prod 132:45-56

Schumacher K, Sands RD (2007) Where are the industrial technologies in energy?economy models? An innovative CGE approach for steel production in Germany. Energy Economics 29 (4):799-825

Tukker A, Bulavskaya T, Giljum S, de Koning A, Lutter S, Simas M, Stadler K, Wood R (2014) The global resource footprint of nations. Carbon, water, land and materials embodied in trade and final consumption calculated with EXIOBASE 2.1. Leiden/Delft/Vienna/Trondheim. This booklet was produced in the context of the project 'Compiling and Refining of Economic and Environmental Accounts' (CREEA), funded by the EU's 7th Framework Programme

UNEP (2016) Global material flows and resource productivity. An assessment study of the UNEP International Resource Panel. H. Schand1, M. Fischer-Kowalski, J. West, S. Giljum, M. Dittrich, N. Eisenmenger, A. Geschke, M. Lieber, H. P. Wieland, A. Schaffartzik, F. Krausmann, S. Gierlinger, K. Hosking, M. Lenzen, H. Tanikawa, A. Miatto, and T. Fishman. Paris, United Nations Environment Programme

UNEP (2017) Resource Efficiency: Potential and Economic Implications. A report of the International Resource Panel. Ekins, P., Hughes, N., et al.

USGS (2015) Mineral commodity summaries 2015: U.S. Geological Survey, 196p., http://dx.doi.org/10.3133/ 70140094

Wiedmann T, Schandl H et al (2015) The material footprint of nations. PNAS 112(20):6271-6276. doi: 10.1073/pnas.1220362110

World Steel Association (2015) Global steel market outlook, OECD steel committee meeting. Available from: https://www.oecd.org/sti/ind/Item\%204b_2\%20-\%20worldsteel_GlobalSteelMarketOutlook.pdf

Yamazaki (2011) Effects of $\mathrm{CO} 2$ emissions trading on steel scrap recycling: a simulation analysis using a computable general equilibrium model. Mater Trans 52(3):498-506

Zhou X, Ambiyah A, Kojima S, Shirakawa H (2014) Accounting for the carbon footprints and embodied primary resources using multi-region input-output analysis. Full paper presentation at the 21 st International Input-Output Conference. 2013 